\title{
Formulation and Evaluation of Transdermal Patches Containing Glimipiride
} Ningule Ganesh M., Nagoba Shivappa N.*, Shaikh Atiya L., Wadulkar Raghunath D., Deshmukh Aditye Y. Channabasweshwar Pharmacy College, Latur, Maharashtra, India

\section{*Corresponding author : Dr. Nagoba Shivappa N. M. Pharm, Ph.D. Associate Professor and Head, Department of} Pharmaceutics, Channabasweshwar Pharmacy College, Kava Road, Latur-413512, Dist. Latur. (MS)

\begin{abstract}
The purpose of this research was to develop a matrix-type transdermal therapeutic system containing drug Glimepride with different ratios of hydrophilic and hydrophobic polymeric systems by the solvent evaporation technique. Different concentrations of oleic acid and isopropyle myristate were used to enhance the transdermal permeation of glimipride.

Matrix type transdermal patches prepared by using different ratio of Eudragit RS100, HPMC100M, by using solvent evaporation techniques. All the prepared formulation were subjected to evaluation studies i.e., weight variation, thickness, drug content, moisture content, moisture uptake, flatness and in-vitro drug release. The physicochemical compatibility of the drug and the polymers studied by differential scanning calorimetry and infrared spectroscopy suggested absence of any incompatibility. Compatibility study between drug and polymer can be done by FTIR. From the all formulation batch F3 was optimized formula. Shows linear zero order release for $24 \mathrm{hrs}$ with cumulative \% drug diffusion of $88.34 \%$ from $4 \mathrm{~cm}^{2}$ patches. It is concluded that concentration of polymer (HPMC100M) when increases into primary layer, then In-vitro diffusion rate also increases and concentration of Eudragit Rs100 when increases, the drug diffusion decreases. It provides better controlled drug release for patch.
\end{abstract}

Keywords : Glimepiride, Matrix Type Transdermal Patch, Eudragit RS 100, In-Vitro Permeation Study

\section{INTRODUCTION}

Transdermal drug administration generally refers to topical application of agents to healthy intact skin either for localized treatment of tissues underlying the skin or for systemic therapy. For transdermal products the goal of dosage design is to maximize the flux through the skin into the systemic circulation. Transdermal drug delivery has many advantages over the oral route of administration such as improving patient compliance in long term therapy, bypassing first-pass metabolism, sustaining drug delivery, maintaining a constant and prolonged drug level in plasma, minimizing inter- and intra patient variability, and making it possible to interrupt or terminate treatment.

Development of a transdermal delivery system for existing drug molecules not only improves the drug's performance in terms of safety and efficacy but also therapeutic benefit and improves patient compliance. It is defined as self-contained, discrete dosage forms which are also known as "patches", when patches are applied to the intact skin, deliver the drug through the skin at a controlled rate to the systemic circulation.

Transdermal patch is a medicated adhesive patch which is placed directly above the skin to deliver a exact dose of medication through the skin with a predetermined rate of release to reach into the 
bloodstream. Skin patch (Transdermal patch) uses a special membrane to control the rate at which the liquid drug contained in the reservoir within the patch can pass through the skin and into the Bloodstream. Delivery of drug not only in controlled manner but also permits continuous input of drugs with short biological half-lives and removes pulsed entry into systemic circulation. controlled release offers by using transdermal drug delivery into the patient\& enables a steady blood-level profile in order to reduced systemic side effects and sometimes effortless and offer multi-day dosing.

\section{Advantages:}

1. In TDDS we can able to deliver the drug in to the blood stream with required quantity (dose) to produce therapeutic efficacy.

2. Steady permeation of drug across the skin will maintain the drug level in serum, often a goal of therapy.

3. It is one of alternative drug delivery system for patients who can't able to tolerate oral dosage forms. Able to administer the drug in unconscious patients by using the TDDS.

4. Drugs that irritate the GIT, produces nausea, vomiting and other GIT disturbances can be used in TDDS which is avoid the direct effects of the drug on stomach \& intestine.

5. Most convenient to use.

6. Sustained drug delivery is possible.

7. First pass metabolism has been estimated in TDDS

8. The frequency of administration is minimized.

9. The drug input can be terminated at any point of time by removing transdermal patch.

10. Self-administration is possible.

11. TDDS are non-invasive which avoids many problems in parenteral therapy.

12. It is one of the painless parenteral application drugs.

13. Bioavailability can be improved.

\section{Basic Components of TDDS 8,9}

A transdermal therapeutic system is essentially a multilaminate structure that is composed of following constituents:

1. Drug

2. Polymer matrix

3. Penetration enhancers

4. Adhesives

5. Backing membrane

6. Release linear

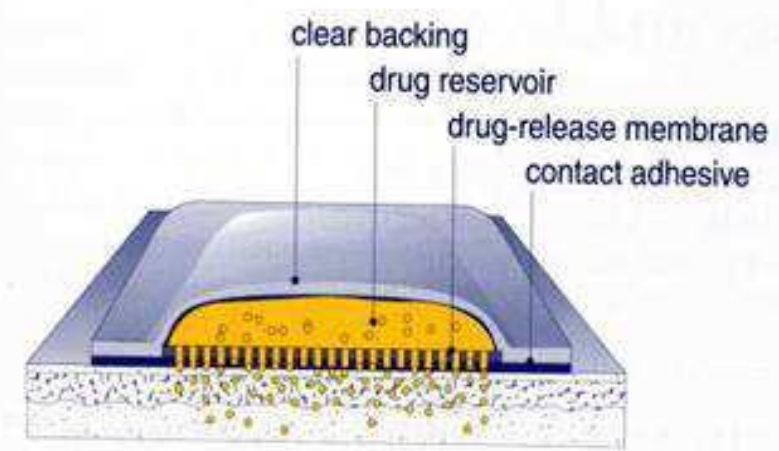

Figure 1. Different layers of transdermal patches

\section{METHODS AND MATERIAL}

Glimepiride was received from Orbicular Pharmaceutical Technology, Pvt. Ltd., Hyderabad., HPMC K 100 M, Eudragit RS 100, was received from Evonic Degussa India Pvt. Ltd. Research Centre, Mumbai., Dimethyl Sulfoxide was received from Emplura Mumbai., Oleic Acid, Polyethylene Glycol 400, Dichloromethane, Methanol was received from Themis laboratory, Mumbai.

Methods : Matrix type transdermal patches containing Glimepiride were prepared by solvent evaporation technique, using different ratios of Eudragit RS 100 and HPMC K 100 M. The polymers were weighed in requisite ratios by keeping the total polymer weight $2.50 \mathrm{gm}$ and allowed for swelling for about 6 hrs. In solvent mixture (1:1 ratio of dichloromethane, methanol). Propylene glycol was 
incorporated as plasticizer and DMSO \& Oleic acid as penetration enhancer. Then the drug solution was added to the polymeric solution, casted on to Petri plate of surface area about70 $\mathrm{cm}^{2}$, allowed for air drying overnight followed by vacuum drying for 8-10

\section{Formulation table}

hr. The entire sheet was cut into small patches with an area of $3.14 \mathrm{~cm}^{2}$ i.e. with a diameter of $2 \mathrm{~cm}$. About 10 patches were obtained from each sheet.

\begin{tabular}{|c|c|c|c|c|c|c|c|c|}
\hline \multirow{3}{*}{ Batches } & $\begin{array}{c}\text { Drug } \\
(\mathbf{m g})\end{array}$ & $\begin{array}{c}\text { HPMC } \\
\text { K 100 } \\
\text { M (mg) }\end{array}$ & $\begin{array}{c}\text { EUDRAGI } \\
\text { T RS 100 } \\
(\mathbf{m g})\end{array}$ & $\begin{array}{c}\text { Olei } \\
\text { Acid } \\
(\mathbf{m l})\end{array}$ & $\begin{array}{c}\text { PEG } \\
\mathbf{4 0 0} \\
(\mathbf{m l})\end{array}$ & $\begin{array}{c}\text { ISOPR } \\
\text { OPYLE } \\
\text { MYRIS } \\
\text { TATE }\end{array}$ & $\begin{array}{c}\text { DCM } \\
(\mathbf{m l})\end{array}$ & $\begin{array}{c}\text { METHANOL } \\
(\mathbf{m l})\end{array}$ \\
\hline \hline F1 & 20 & 000 & 500 & $20 \%$ & $25 \%$ & $20 \%$ & 5 & 5 \\
\hline \hline F2 & 20 & 100 & 400 & $20 \%$ & $25 \%$ & $20 \%$ & 5 & 5 \\
\hline \hline F3 & 20 & 200 & 300 & $20 \%$ & $25 \%$ & $20 \%$ & 5 & 5 \\
\hline
\end{tabular}

(PEG-polyethylene glycol, DMSO-Dimethyl A 10mg of Glimepiride was accurately weighed and sulfoxide, DCM- Dichloromethane) was first dissolved in $35 \mathrm{ml}$ methanol solutions. These solutions then diluted using phosphate-buffer $\mathrm{pH}-7.4$

Preliminary studies:

I. Determination of $\lambda \max$ : to $100 \mathrm{ml}$. UV spectrum was recorded in the wavelength range $200-400 \mathrm{~nm}$.

III. Preparation of calibration curve for Glimepiride

\begin{tabular}{|c|c|c|c||c|c||c|c|c|}
\hline \multirow{3}{*}{ Batches } & $\begin{array}{c}\text { Drug } \\
(\mathbf{m g})\end{array}$ & $\begin{array}{c}\text { HPMC } \\
\text { K 100 } \\
\text { M (mg) }\end{array}$ & $\begin{array}{c}\text { EUDRAGI } \\
\text { T RS 100 } \\
(\mathbf{m g})\end{array}$ & $\begin{array}{c}\text { Olei } \\
\text { Acid } \\
(\mathbf{m l})\end{array}$ & $\begin{array}{c}\text { PEG } \\
\mathbf{4 0 0} \\
(\mathbf{m l})\end{array}$ & $\begin{array}{c}\text { ISOPR } \\
\text { OPYLE } \\
\text { MYRIS } \\
\text { TATE }\end{array}$ & $\begin{array}{c}\text { DCM } \\
(\mathbf{m l})\end{array}$ & $\begin{array}{c}\text { METHANOL } \\
(\mathbf{m l})\end{array}$ \\
\hline \hline F1 & 20 & 000 & 500 & $20 \%$ & $25 \%$ & $20 \%$ & 5 & 5 \\
\hline \hline F2 & 20 & 100 & 400 & $20 \%$ & $25 \%$ & $20 \%$ & 5 & 5 \\
\hline \hline F3 & 20 & 200 & 300 & $20 \%$ & $25 \%$ & $20 \%$ & 5 & 5 \\
\hline
\end{tabular}


Concentration was made using the phosphate buffer $\mathrm{pH} 7.4$ media. It was analyzed spectrophotometrically by measuring the absorbance at $228 \mathrm{~nm}$ wavelength. The absorbance value are shown in table no. The figure no shows standard calibration curves with slope 0.0717 and regression value 0.9999 . The curve was found to be linear in the ranGE12 $\mu \mathrm{g} / \mathrm{mlat}$.the drug solution of with concentration of $100 \mu \mathrm{g} / \mathrm{ml}$ was

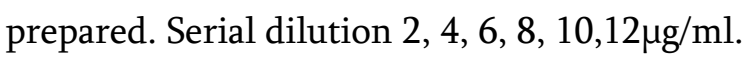

\section{Fourier Transform Infrared (FT-IR) Spectral}

Studies of Glimepiride: The spectrum of Glimepiride was obtained by means of a FTIR spectrophotometer. FT-IR spectra of Glimepiride drug were recorded on Agilent cary $630 \mathrm{~nm}$ FTIR Spectrophotometer. Sample was placed in sample holder; the scanning was performed between $4000 \mathrm{~cm}-1$ to $400 \mathrm{~cm}-1$ range. IV. Drug excipients interaction studies: The compatibility of drug and polymers under experimental conditions is important prerequisite before formulation. It is essential to verify that the drug does not react with the polymer and excipients in process condition and does not affect the shelf-life of product or any other unwanted effects on the formulation. The physical mixture of drug \& polymers were used for determination of Infrared spectrums.

\section{Evaluations of transdermal Patches:}

\section{Physical Appearance:}

The formulated films were examined for colour, clearness, softness and elasticity.

\section{Thickness:}

It was précised by digital Vernier calipers. Three reading were taken for standard deviation after thickness measured at five various site of patch. The thickness of Glimepiride patches were between $110-122 \mu \mathrm{m}$.

\section{Weight Variation Test:}

Firstly, the three patches were chosen randomly from all batches then three films were chosen and weighed separately from individual formulation and calculated the mean for weight variation test and standard weight was estimated. The weight variation of Glimepiride patches were in between 250 to $280 \mathrm{mg}$. This showed uniformity in weight of patches while the \% drug content of Glimepiride in patches were between 95.00 to $95.25 \pm 0.84 \%$ this shows passable drug content in patches.

\section{Folding Endurance}

The folding endurance of patches were found to be satisfactory between $120.66 \pm 2.42$ to $128.66 \pm 0.48$.This shows that patches would maintain their integrity and not break easily during handling. The tensile strength was found to be in the range of 0.31 to $1.31 \mathrm{~kg}^{2} \mathrm{~mm}^{2}$. As the concentration of hydrophilic polymer HPMC E15 was increased the tensile strength was found to be increased. All film showed $100 \%$ flatness. It was calculated physically for formulated patches. The patches were cut and constantly folded over at similar position till it was broken. Number of times the patch could be folded over at similar position without breaking or cracking given the value of folding Endurance.

\section{Flatness}

The films were cut from formulated patches longitudinally and lengths of individual films were calculated. The difference in length due to the nonuniformity in flatness was measured. It was estimated through measured constraint of films and zero percent constraint was considers to be equals to a hundred percent flatnes.

$$
\text { Constriction }(\%)=\underline{\mathrm{L} 1-\mathrm{L} 2} \times 100
$$

L2

\section{Where,}

$$
\begin{aligned}
& \text { L1:- Initial lengths of film } \\
& \text { L2:- Final lengths of film }
\end{aligned}
$$




\section{Determination of Glimepiride content:}

A sample of $1 \mathrm{~cm} \mathrm{x} 1 \mathrm{~cm}$ of the patch was cut and weighed accurately. Each sample was dissolved in $100 \mathrm{~mL}$ of phosphate buffer solution and stirred for 24 hour using magnetic stirrer. The solution was analyzed by UV-VIS spectrophotometer at $220 \mathrm{~nm}$. The total content of Glimepiride was calculated. The value was mean $+\mathrm{SD}$ of the three determinations.

\section{Moisture Absorption Study:}

The films were weighed accurately and placed in desiccators containing $100 \mathrm{ml}$ of saturated solution of aluminium chloride $(79.50 \% \mathrm{RH})$. After 3 days, the films were taken out and weighed, the percentage of moisture uptake was calculated as the difference between final and initial weight with respect to initial weight.

\section{Percentage moisture uptake $=[$ Final weight-Initial weight/ initial weight] $\times 100$}

The moisture absorption in the formulations is ranged from $1.45 \pm 0.50$ to $5.46 \pm 0.54 \%$ (for formulation $\mathrm{F}$ series respectively)

\section{Moisture Content:}

The patches were weighed and kept in a desiccator containing calcium chloride at 40o C for $24 \mathrm{hr}$. The final weight was noted when there was no further change in the weight of patch. The percentage of moisture content was calculated as a difference between initial and final weight with respect to initial weight.

\section{Percentage moisture content $=[$ Initial weight - Final weight/ Final weight] $\times 100$}

The moisture content in the patches was ranged from $1.37 \pm 0.24$ to $2.55 \pm 0.66 \%$ (for formulation F series and formulation respectively)

\section{Tensile strength:}

The instrument was designed such that it had horizontal wooden platform with fixed scale and attachment for two clips that hold transdermal patch under test. Out of two clips one was fixed and other was movable. Weights were hanged to one end of pulley and the other end of pulley was attached with movable clip. The wooden platform was such fitted that it would not dislocate while the test was running. Three strips of patch were cut having $4 \mathrm{~cm}$ length and $0.5 \mathrm{~cm}$ breadth. The thickness and breadth of strips were noted at there sites and average value was taken for calculation. The strips were marked with ink $2 \mathrm{~cm}$ apart and $1 \mathrm{~cm}$ each end. Each strip was fit in clips in such a way that marking would be just visible. The rate of change of stress was kept constant with the instrument of $0.5 \mathrm{gm}$ per $2 \mathrm{~min}$. The elongation was observed and the total weights taken were used for calculation. The tensile strength was calculated by using following formula.

$$
\text { Tensile stress }(\mathrm{S})=\frac{\text { Applied force }}{\text { Cross sectional area }}=\frac{\mathrm{m} \times \mathrm{g}}{\mathrm{b} \times \mathrm{t}}
$$

Where,

$\mathrm{S}=$ tensile stress in 980 dynes $/ \mathrm{cm}^{2}$

$\mathrm{m}=$ mass in grams

$\mathrm{g}=$ acceleration due to gravity $\left(980\right.$ dynes $\left./ \mathrm{cm}^{2}\right)$

$\mathrm{b}=$ breadth of strip in centimeters

$\mathrm{t}=$ thickness of strip in centimeters

\section{Weight variation and drug content}

The weight variation of Glimepiride patches were in between 250 to $280 \mathrm{mg}$. This showed uniformity in weight of patches while the \% drug content of Glimepiride in patches were between 95.00 to $95.25 \pm 0.84 \%$ this shows passable drug content in patches 


\section{In-Vitro Drug Release Study:}

Franz diffusion cell consist of an upper donor compartment and the lower receptor compartment surrounded by water jacket to maintain the temperature of receptor phase at $32 \pm 1^{\circ} \mathrm{C}$ (USP). The uniformity of the solution in the receptor phase was maintained by stirring at a speed of $600 \mathrm{rpm}$ (approx.) using a tiny Teflon coated magnetic bead. The volume of the receptor compartment was maintained at $60 \mathrm{ml}$. The receptor compartment was provided with the sampling port from one side to withdraw samples at the predetermined time intervals for estimation of drug content by UV spectrophotometer. The receptor medium was phosphate buffer saline (PBS) $\mathrm{pH} \quad 7.4$ containing 30\%v/v PEG-400 as solubilizer.

\section{Permeation studies:}

Rat dorsal skin was excised. Hair and underlying tissues were removed with a sharp scissors. Skin was washed thoroughly with distilled water and normal saline. It was soaked in the normal saline overnight and washed several times before use. The skin was then cut into appropriate size and mounted between the compartments of the diffusion cell with stratum corneum facing the donor compartment. It was left overnight on the receptor fluid for stabilization and optimization. The matrix formulation to be tested was cut into $1 \mathrm{~cm}^{2}$ patch $(\mathrm{n}=3)$ and was placed over the optimized skin. It was then covered with aluminium foil as the occlusive backing. The donor compartment was clamped over it with the help of springs, making sure that there were no air bubbles in the receptor chamber. Samples of $3 \mathrm{ml}$ were withdrawn at predetermined time intervals upto 48 hrs. Fresh receptor fluid was added to the receiver compartment to maintain a constant volume. The filtered samples were then analyzed using UV double beam spectrophotometer (Schimadzu) at maxima of $220 \mathrm{~nm}$. Linearity was demonstrated from 2 to $22 \mu \mathrm{g} / \mathrm{ml}(\mathrm{R} 2>0.999)$
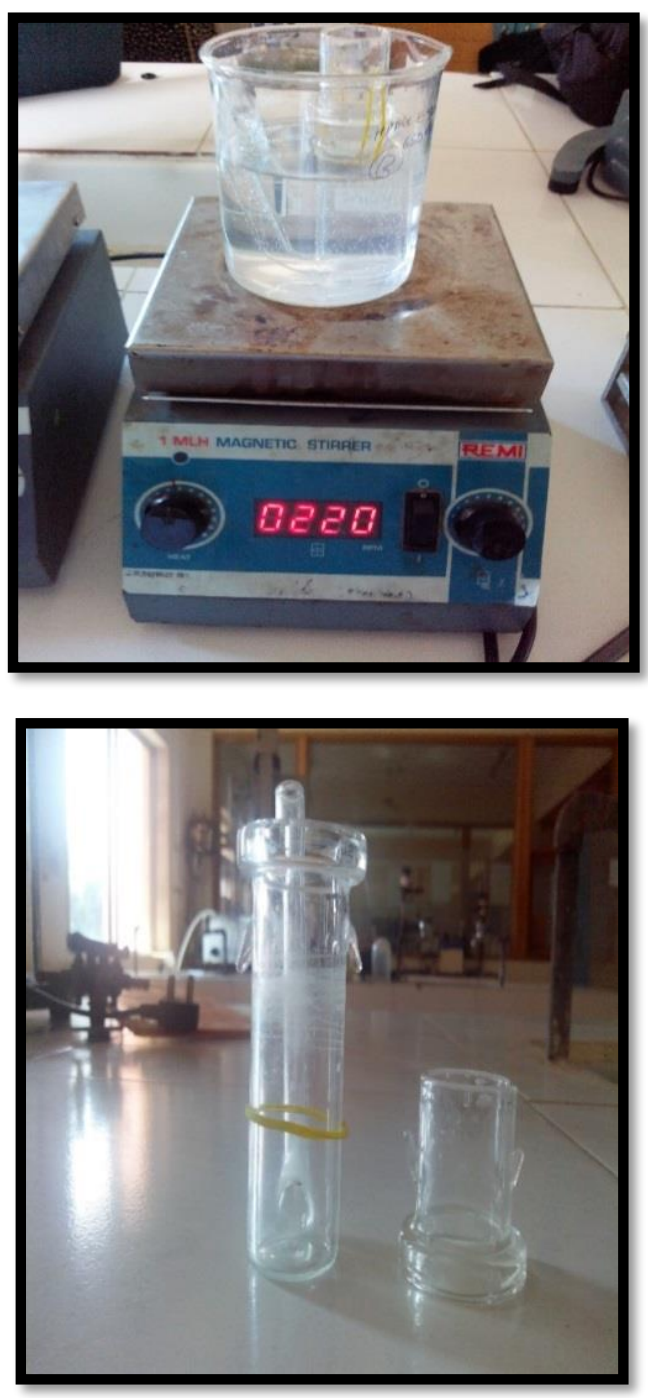

Figure 1: Diffusion Cell

\section{RESULTS AND DISCUSSION}

1) Preliminary studies:

Determination of $\lambda$ max:

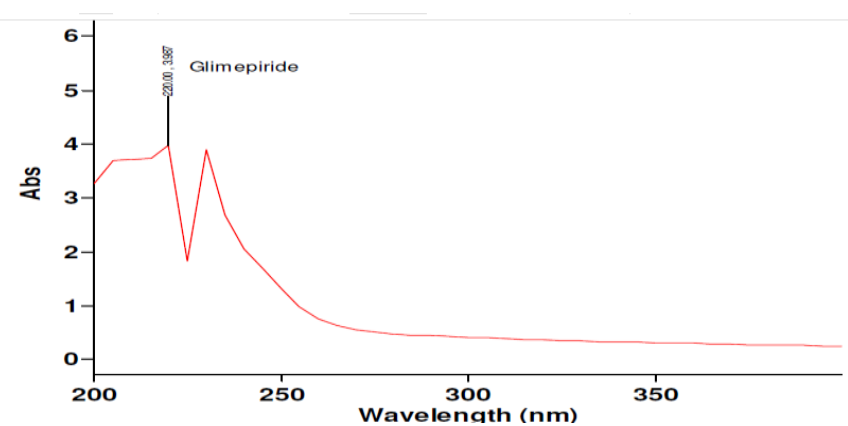


Standard calibration curve of Glimepiride:

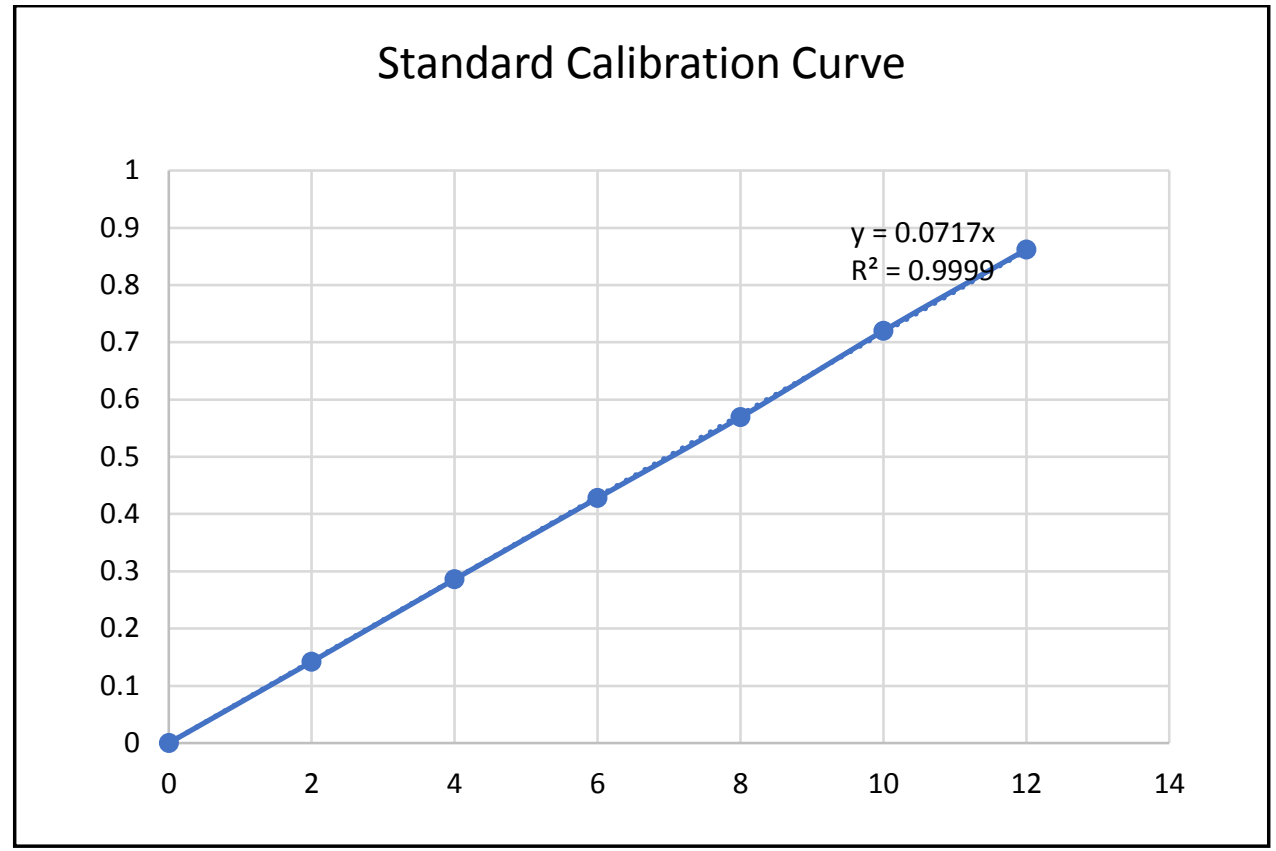

Figure $2: \lambda$ max of Glimepiride

Standard calibration curve of Glimepiride:

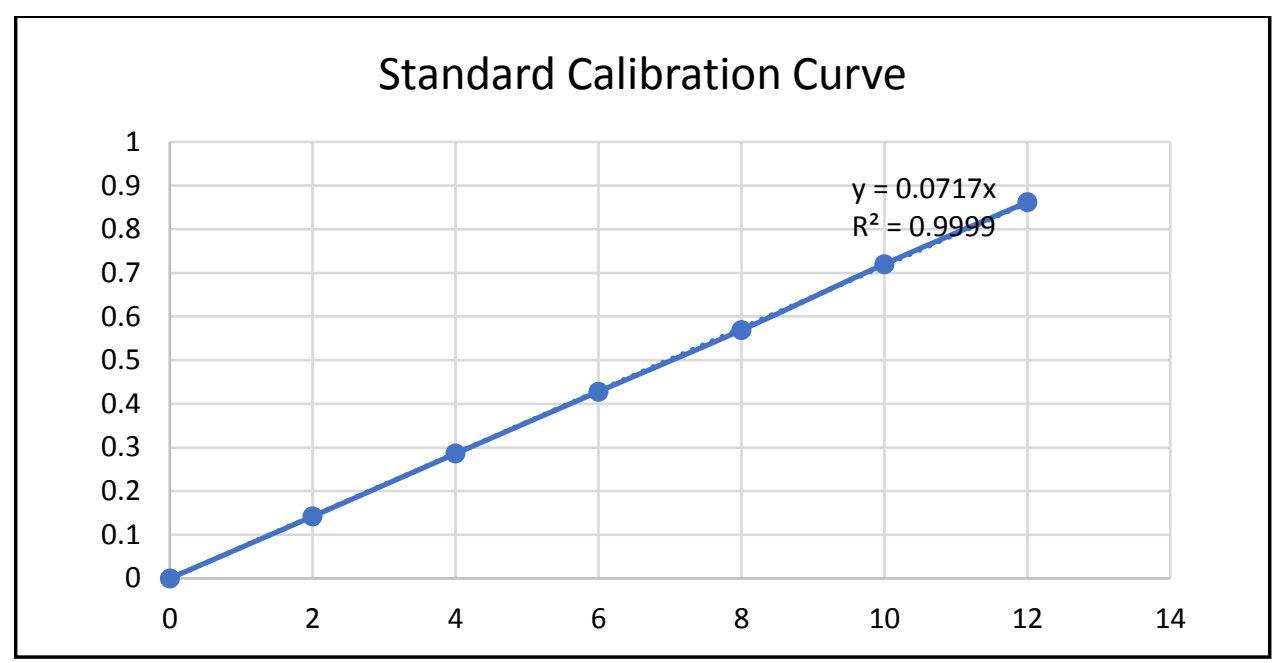

Figure 3 : Standard calibration curve 


\section{Drug \& Excipients Compatibility:.}

\section{A) FTIR Spectra of Glimepiride}

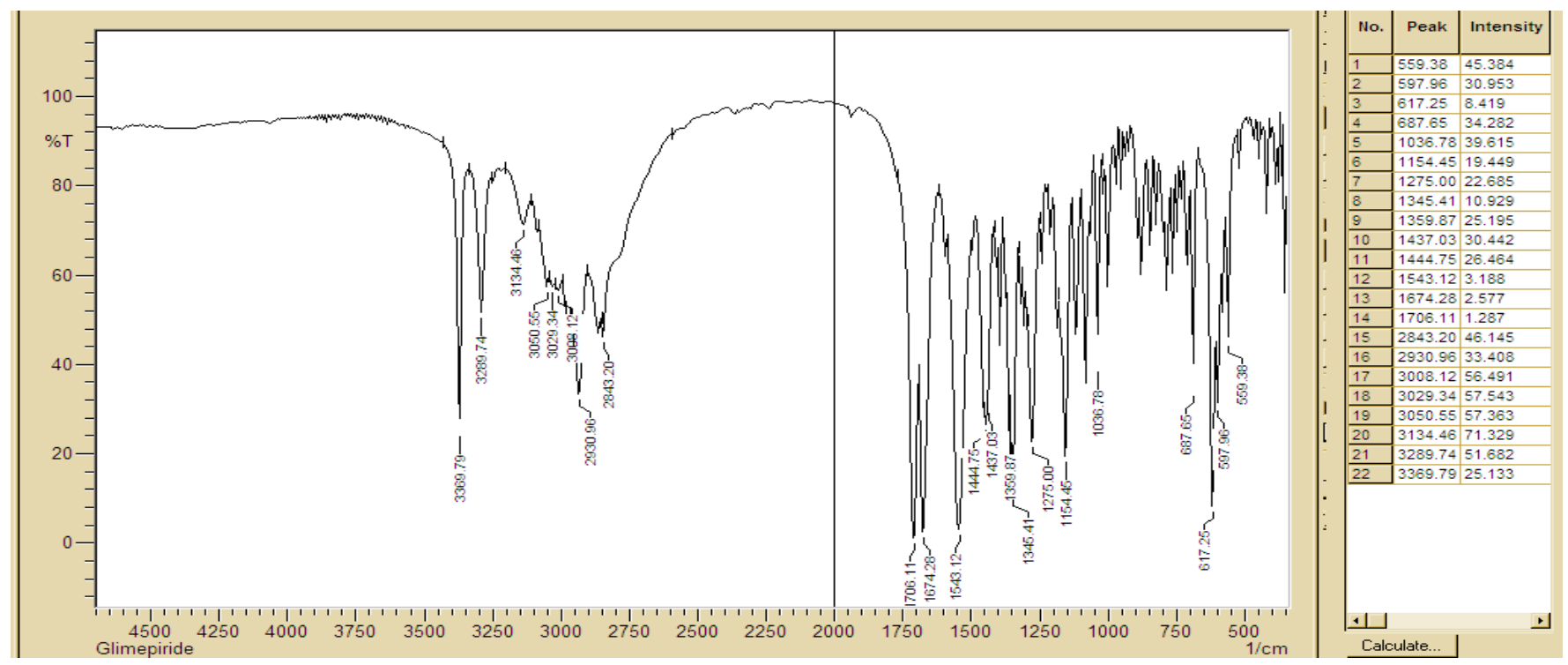

Figure 4 : FT-IR Spectra ofGlimepiride

B) Compatibility studies between Drug \& excipients:

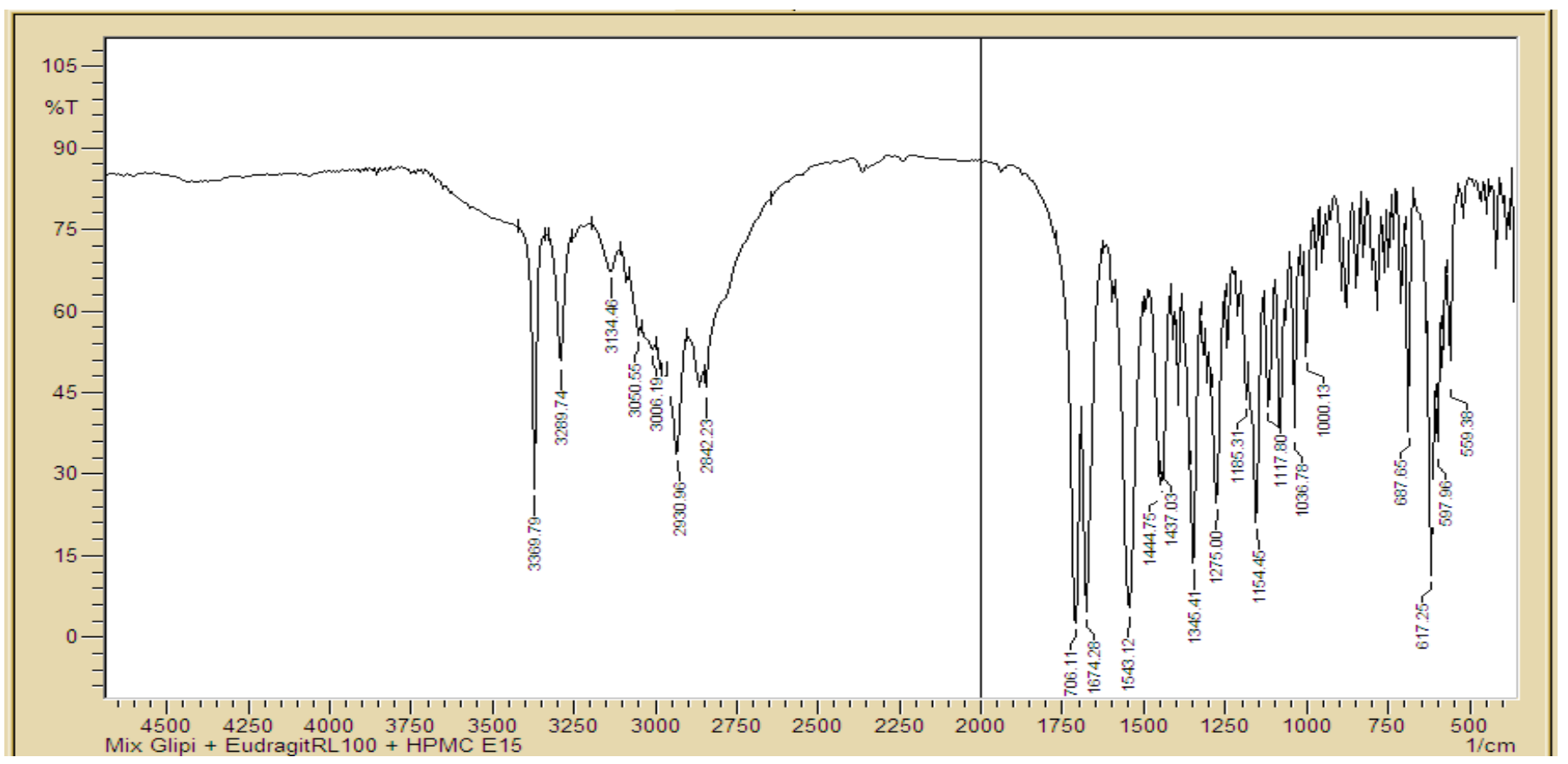

Figure 5: Compatibility studies between Drug \& excipients 
Evaluation of Transdermal film :

A. Physicalappearance:

Table.1: physical appearance of batch F1 to F3

\begin{tabular}{|l|l|l|l|l|}
\hline $\begin{array}{l}\text { Formula } \\
\text { tion }\end{array}$ & Flexibility & Smoothness & Transparency & Stickiness \\
\hline F1 & Flexible & Smooth & Opaque & Non-Sticky \\
\hline F2 & Flexible & Smooth & Opaque & Non Sticky \\
\hline F3 & Flexible & Smooth & Opaque & Non Sticky \\
\hline
\end{tabular}

B. Thickness: Table No.2: Thickness of batch F 1 to F3

\begin{tabular}{|l|l|}
\hline Formulation & Thickness $(\mu \mathrm{m})$ \\
\hline F1 & $110 \pm 1.22$ \\
\hline F2 & $115 \pm 1.22$ \\
\hline F3 & $122 \pm 1.69$ \\
\hline
\end{tabular}

All the value represented mean $\pm S . D(n=3)$

C. Folding endurance, flatness and tensilestrength

Table 3 : Folding endurance, Flatness, Tensile strength of batch F1 to F3

\begin{tabular}{|c||c|c|c|}
\hline \multirow{2}{*}{ Formulation Code } & \multicolumn{3}{|c|}{ Parameters } \\
\cline { 2 - 4 } & $\begin{array}{r}\text { Folding } \\
\text { Endurance }\end{array}$ & Flatness & $\begin{array}{r}\text { Tensile } \\
\text { Strength } \\
\mathrm{kg}^{2} \mathrm{~mm}^{2}\end{array}$ \\
\hline F1 & $120.5 \pm 2.42$ & $100 \%$ & $0.31 \pm 0.038$ \\
\hline F2 & $125.7 \pm 0.48$ & $100 \%$ & $0.66 \pm 0.208$ \\
\hline F3 & $128.6 \pm 0.48$ & $100 \%$ & $1.31 \pm 0.311$ \\
\hline
\end{tabular}


D. Moisture Content and Moisture Absorption Studies

\begin{tabular}{|l|l|l|}
\hline Formulation & Moisture content & Moisture absorption \\
\hline F1 & $1.27 \pm 0.24 \%$ & $1.45 \pm 0.50 \%$ \\
\hline F2 & $1.53 \pm 0.55 \%$ & $3.45 \pm 0.52 \%$ \\
\hline F3 & $2.48 \pm 0.66 \%$ & $5.46 \pm 0.54 \%$ \\
\hline
\end{tabular}

Table 4: Moisture content and Moisture absorption studies of batch F1 to F3

E. Weight variation and drug content

\begin{tabular}{|l|l|c|}
\hline \multirow{2}{*}{ Formulation } & Parameters \\
\cline { 2 - 3 } & Average weight(Mg) & \% Drug content \\
\hline F1 & $248.33 \pm 2.49$ & $95.00 \pm 0.34$ \\
\hline F2 & $256.66 \pm 2.867$ & $94.31 \pm 0.37$ \\
\hline F3 & $262.83 \pm 3.84$ & $95.25 \pm 0.84$ \\
\hline
\end{tabular}

(value represented mean \pm S.D $(n=3)$

Table 5 : Weight variation and drug content of batch F1 to F3

F. In vitro skin permeation study:

\begin{tabular}{|c|c|c|c|}
\hline Time & $\begin{array}{l}\text { Cumulative } \\
\text { \%drugD } \\
\text { iffuse }\end{array}$ & $\begin{array}{l}\text { Cumulative } \\
\text { \%drugDiffuse }\end{array}$ & $\begin{array}{l}\text { Cumulative } \\
\text { \%drugDiffuse }\end{array}$ \\
\hline 0 & 0 & 0 & 0 \\
\hline 1 & 1.07 & 1.47 & 4.51 \\
\hline 2 & 2.26 & 2.58 & 9.27 \\
\hline 3 & 3.45 & 3.74 & 25.9 \\
\hline 4 & 4.87 & 4.98 & 37.24 \\
\hline 5 & 6.98 & 8.24 & 49.65 \\
\hline 6 & 11.7 & 12.38 & 57.52 \\
\hline 7 & 15.11 & 16.3 & \\
\hline
\end{tabular}




\begin{tabular}{|c|c|c|c|}
\hline 8 & 19.02 & 21.17 & 66.84 \\
\hline 9 & 25.45 & 27.41 & 68.58 \\
\hline 10 & 31.75 & 34.98 & 69.65 \\
\hline 11 & 36.61 & 40.18 & 71.79 \\
\hline 12 & 41.14 & 45.41 & 73.98 \\
\hline 13 & 44.4 & 49.93 & 77.33 \\
\hline 14 & 47.29 & 53.91 & 79.43 \\
\hline 15 & 49.87 & 56.23 & 81.13 \\
\hline 24 & 62.89 & 70.68 & 88.34 \\
\hline
\end{tabular}

Table 6 : In-Vitro drug release F1-F3 batch

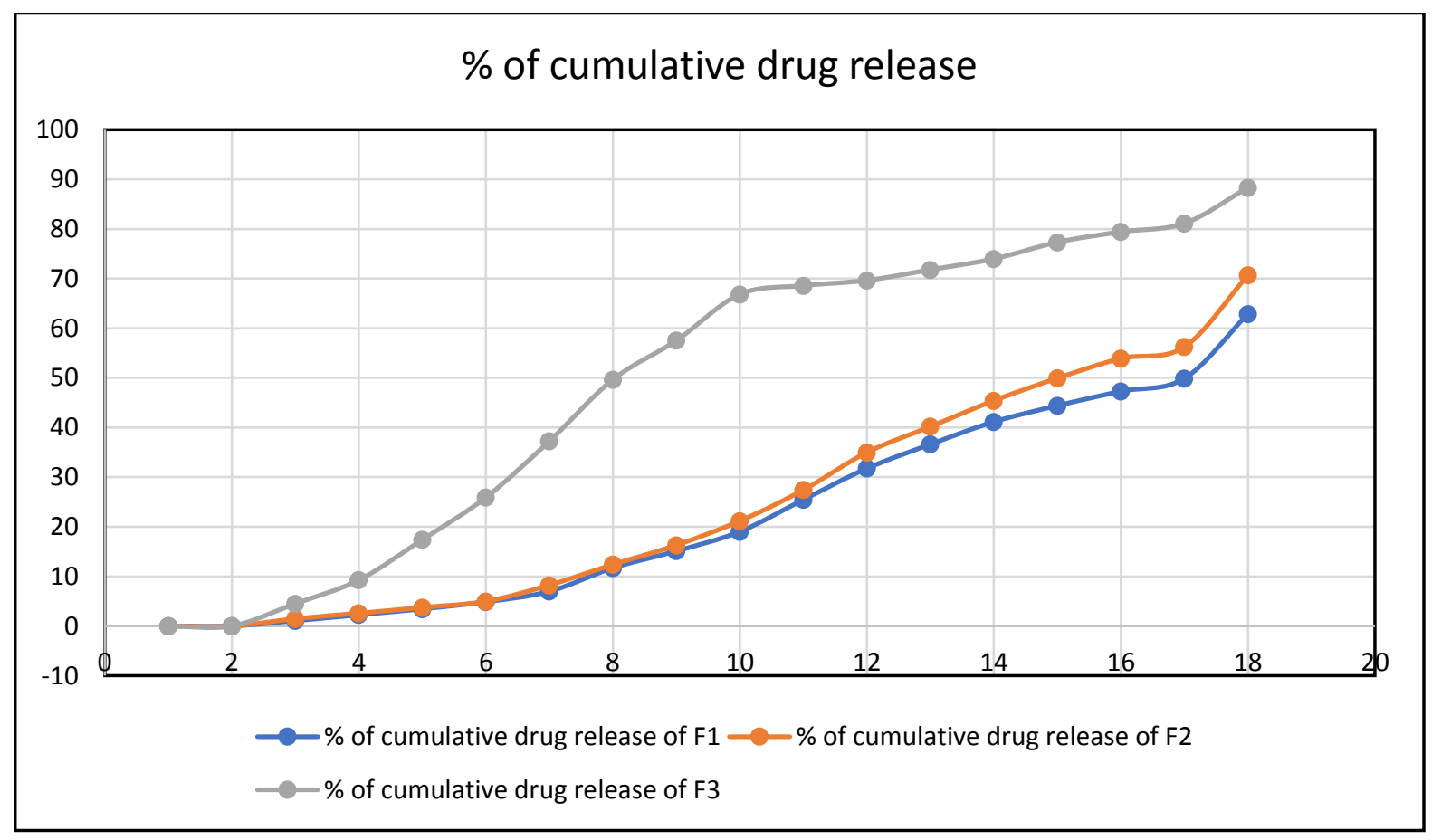

Figure $.6: \%$ of cumulative drug release

\section{VI.CONCLUSION}

The method of preparation of transdermal patches of glimipiride presented in this research work is simple. All formulation also showed good physicochemical properties like thickness, weight variat release data showed that drug release from the patch formulation have been affected by types of polymer and concentration of polymer. Effect of penetration enhancer like oleic acid and isopropyl myristate have been checked on in-vitro permeation of drug. These studies indicated that as the concentration of penetration enhancer increased drug permeation was increased. The concentrations of HPMC K100 M when increased into primary layer In vitro diffusion rates were also increased and also as concentration of 
Eudragit RS100 when increased, the drug diffusion rate was decreased and vice versa. Batch F3 was the optimized formulation showing uniform thickness, good tensile strength, drug content uniformity and good folding endurance. The formulation F3 showed linear zero order release for 24 hours with cumulative \% drug diffused of 88.34 from $4 \mathrm{~cm}^{2}$ patches of batch F3.

\section{VII.ACKNOWLEDGEMENT}

Glimepiride was received from Orbicular Pharmaceutical Technology, Pvt. Ltd., Hyderabad, HPMC K 100 M, Eudragit RS 100, was received from Evonic Degussa India Pvt. Ltd. Research Centre, Mumbai., Isopropyle myristate was received from Emplura Mumbai., Oleic Acid, Polyethylene Glycol 400, Dichloromethane, Methanol was received from Themis laboratory, Mumbai.

\section{REFERENCES}

[1]. HimanshiTanwar and Ruchika Sachdeva, transdermal drug delivery system: a review, ijpsr (2016), vol. 7, issue 6

[2]. Richa Sachan, Meenakshi Bajpai, transdermal drug delivery system: a review, International Journal of Research and Development in Pharmacy and Life Sciences Available online at http//www.ijrdpl.com December - January, 2013, Vol. 3, No.1, pp 748-765 ISSN: 2278-0238

[3]. Audumbar Digambar Mali at al., An updated review on transdermal drug delivery systems, International Journal of Advances in Scientific Research ISSN: 2395-3616 (Online) Journal DOI: 10.7439/ijasr.

[4]. Zainab E. Jassim, Halah Talal Sulaiman, Transdermal drug delivery system: A review , Article in Journal of Pharmacy Research · May 2018.

[5]. Mohit Dangwal, a review article on transdermal drug delivery system, pharmatutor.
[6]. V. Kalvimoorthi1*, M. Rajasekaran2, Transdermal Drug Delivery System: an overview ,international journal of pharmaceutical and chemical sciences ISSN: 2277-5005

[7]. Angilicam Avinash*, MaduMounica, a comprehensive review on transdermal drug delivery system, World Journal of Pharmaceutical Research, Volume 5, Issue 11, 478-507. Review Article ISSN 2277-7105.

[8]. Guy, Richard H, Hadgraft, Jonathan; Transdermal Drug Delivery Second Edition Published by Informa Health Care. 2002: 322

[9]. Govil SK. In: Drug Delivery Devices, P. Tyle (Ed.), Marcel Dekker, New York. 1988: 388.

[10]. Mutalik, \& N. Udupa, Glibenclamide transdermal patches: physicochemical, pharmacodynamic, and pharmacokinetic evaluations. J Pharm Sci.Jun. 2004; 93(6) :1577-94.

[11]. S. Mutalik, \& N. Udupa, Pharmacological evaluation of membrane-moderated transdermal system of glipizide. Clin. Exp. Pharmacol. Physiol. 2006;33(12):17-26.

[12]. Santosh Girani, Dhaval Patel, ManteshKavatekarformulation and evaluation of matrix type transdermal therapeutic system containing Glibenclamide ejpmr, 2016,3(5), 556-569.

[13]. Shailesh T. Prajapati, Charmi G. Patel, and Chhagan N. Patel Research Article Formulation and Evaluation of Transdermal Patch of RepaglinideInternational Scholarly Research Network ISRN Pharmaceutics Volume 2011, page No.9

\section{Cite this article as :}

Muhammad Ardiansyah, Sri Setya Handayani, "The Influence of Climate Organization and Individual Characteristics on the Employees' Performance of Regional Office of Sulawesi, Maluku, and Its Alignments", International Journal of Scientific Research in Science and Technology (IJSRST), Online ISSN : 2395-602X, Print ISSN : 2395-6011, Volume 6 Issue 4, pp. 261-275, July-August 2019. Available at doi : $\quad$ https://doi.org/10.32628/IJSRST196445 Journal URL : http://ijsrst.com/IJSRST196445 